\title{
Innovative Products Commercialization and Social Aspects
}

\author{
Budovich Lidia Sergeevna*
}

\author{
Department of Economics and Innovative Entrepreneurship, MIREA - Russian Technological University \\ (RTU MIREA), Moscow, Russian Federation
}

\begin{abstract}
Ideation, research, and technological innovation are valuable when they lead to wealth creation. Commercialization is a way to tie science to economics and create wealth from innovation. Success in technology development and commercialization requires a combination of several factors, including creative thinking, appropriate technical knowledge, entrepreneurial thinking and spirit, and financial resources. But it is rare for a single person to have all of these characteristics. Therefore, the best way to successfully commercialize technology is to create a team of four different personalities with the above characteristics: These four personalities are inventor/innovator, investor, technology, and entrepreneur. This article examines the definitions and concepts of commercialization and points to social and economic factors in the commercialization process - from ideation to the development of success and growth. Then proposed the formation of an innovation team as one of the strategies for commercialization success and expresses the characteristics of the innovation team and its members and their role in different stages of commercialization. Finally, to achieve more and better achievements in the field of commercialization, suggestions are presented according to the existing conditions.
\end{abstract}

Keywords: Innovative product, commercialization, social, employment.

\section{INTRODUCTION}

Conducting research and study for the development of technology and finally, its commercialization is one of the inevitable stages of the birth and creation of new technology (Piccarozzi 2017). One of the main reasons for the rapid progress and development of technology in industrialized countries. It has been inside those countries. On the other hand, the inability to commercialize and implement research achievements in new products and processes and market them is one of the major weaknesses of developing countries in the process of industrialization. Studies show that out of about 1000 raw ideas, only one or two ideas succeed in the market (Hudders et al., 2020)

Undoubtedly, the biggest concern of the officials and major decision-makers of any country is the economic situation of that country. The economic growth of any country has a lot to do with creating and improving the economic infrastructure and business environment of that country (Budovich, 2019; Chesalin et al., 2019). Determining the right economic goals and choosing smart strategies and turning them into action plans is an important part of the process, but another factor that is very important in achieving the set goals is the development and facilitation of the business environment that creates, maintains, and improves It plays an important role in the set economic goals.

*Address correspondence to this author at the Department of Economics and Innovative Entrepreneurship, MIREA - Russian Technological University (RTU MIREA), Moscow, Russian Federation; E-mail: budovich@mirea.ru
As more economic activity leads to increased investment, job creation, higher incomes, taxes for the government, and the welfare of society, most countries seek to create a business environment for economic actors. The development of the private sector in an economy is based on a complex set of rules, extensive physical and institutional infrastructure, a stable macroeconomic environment, the development of financial markets, attracting foreign direct investment, the development of small and medium-sized industries, labor market regulations, Learning is based and it does not happen to put this set right together (Belcher \& Schreckenberg 2007; Cillo et al., 2019). Therefore, institutional and infrastructural infrastructure for the development and removal of business barriers is one of the basic requirements for the implementation of this policy.

\section{METHODS}

The A developer and an investor have complete information regarding the technical and commercial characteristics of the innovations. However, in practice, the developer undoubtedly knows more than the entrepreneur about the innovation, so the issue of asymmetric market information inevitably arises. In the market economy conditions, the buyer of innovation cannot test it before making a deal. As a result, he will always have suspicions regarding the quality of the innovation, so he will underprice the product to reduce his risks. It is possible to diminish the asymmetry of innovation quality information by increasing the developer's reputation, as well as by targeting the innovation and informing the potential customer 
(entrepreneur) during the innovative product development process. Entrepreneurs would rather trust the characteristics of an innovation when the developer is well-known or it has a strong reputation in the industry (Spender et al., 2017). An important characteristic of the innovation market is the need for intersectoral innovative communications. For example, the high capabilities of aircraft designers depend on the quality level of new composite materials made by chemical industry workers. Therefore, the rejection of fundamental innovations and the small demand for them may arise due to the lack of an appropriate highquality technology level in another business sector. The essential nature of the innovation market, when an intellectual product is targeted at the identified customer, makes it possible to build innovative communications (relations) following the requirements of the contemporary market. Its main principle is that the manufacturer enters a market not with finished products for an unidentified customer, but with the ability to fulfill the customer's order in a quality manner (Malec et al., 2020). The innovation market is developing as the market of orders that essentially changes the system of relations between sellers and buyers transforming it to a system of innovative communications that reduce risks and allow the creation of specific products (innovations) with a longterm production cycle against guarantees of the customer (investor). Owners of innovations constantly face the task of choosing the best form of economic turnover of the intellectual property.

\section{RESULTS}

The forms of commercialization (involving objects of intellectual property into the economic turnover) are: 1) license transfer; 2) contribution of intellectual property as an intangible asset to the charter capital of an enterprise; 3) management of production and marketing of new products by the developer; 4) foundation of a joint venture; 5) production cooperation; 6) franchising; 7) leasing (financial lease).

License transfer. The main form of commercialization of innovations is the transfer of licenses. A license agreement is an agreement whereby one of the parties (the licensor) has the exclusive right to an intangible asset and acts as the seller, and the other party (the licensee) desires to obtain (buy) permission to use the licensor's rights. The licensor receives remuneration payable as the license royalty, or the license is issued upon a lump-sum payment of its market value. Contribution of intellectual property to the charter capital. The Civil Code of the Russian Federation and the Company Law provides for the possibility of using such a form of innovation commercialization as the contribution of intellectual property as an intangible asset to the charter capital of an enterprise. The contribution to the charter capital of the enterprise can be made based on a right of ownership, economic or operational management. Management of production and marketing of new products by the developer. The development organization can independently manufacture and market a new product. The involvement of only the results of the research phase into the economic turnover reduces the cost of transferred knowledge and makes it difficult for market participants to perceive them. A potential customer should be able to practically evaluate the result of scientific work submitted in the form of a physical object - a new technology sample. What's most important is that the sample must have market demand and at the same time not only satisfy the requirements of the consumer but also make a reasonable profit. The achievement of this goal is not always associated with the high technical level of innovation, surpassing foreign counterparts. It's quite likely that such products may not have effective demand, and products with a relatively low technical level will meet the needs of the market. Therefore, increasing the technical level of the innovation, by all means, should not be a goal in itself, but it should correspond to the effective demand of consumers. If the developers do not have experience and knowledge in the field of economics, finance, legal relations with an investor, etc., to solve this problem they can hire a specialist with experience in the commercialization of intellectual property to perform a wide range of works to analyze the market potential of the innovation, conduct the marketing research, negotiate with funds supporting innovative ventures, develop strategies for cooperation with partners and conducting negotiations, organize promotional and PR activities, etc. If the results of the business idea analysis confirm the feasibility of a new business, it is possible to establish a small innovative enterprise with the participation of an investor employee (or organization) managing the project. The steps for the establishment of a small innovative enterprise are as follows: 1) obtaining a patent for an industrial property; 2) determining the market value of the industrial property with the help of a professional appraiser, that will further be include on books and records of the small innovative enterprise as intangible assets; 3) to conducting market research; 4) preparing a business plan for an innovative project; 5 ) 
searching and taking on a potential investor using a business plan; 6) establishing a new legal entity - a small innovative enterprise - and contributing your patent, registration certificate or only the right to use it as a share into the charter capital, having determined the size of the investor's share in advance; 7) conducting negotiations with the investor and documenting their results in the agreement on buying out the investor's share in the charter capital and the agreement on the intellectual property partition rights made as the result of the operation process of a small innovative enterprise.

It is necessary to agree on buying out the investor's share in the charter capital because in Russia the market of small innovative enterprises shares is practically unoccupied and the investor faces difficulties when trying to exit from the enterprise. The agreement on the intellectual property partition rights shall be concluded due to the fact that scientific research is often required to improve the products and production technology. Therefore, it is important to determine the ownership in advance or allocate shares in a newly created intellectual property asset.

As practice shows in Russia, the small innovative enterprises usually cannot grow to the medium-sized business to become large companies afterward. The introduction of a new product with a potentially large sales volume into the market requires different sources of material, human and financial resources, and a new level of management that the former developers usually can no longer provide. Therefore, cooperation between a small innovative enterprise and a large enterprise may be advantageous even at the early stages of the foundation.

Foundation of a joint venture. If interested partners wish to join efforts, knowledge, and experience for the production of new products in the market, to share the risks, they have no better way than to found a joint venture. Neither form of cooperation creates such a level of interest of the participants in the ultimate success of the project. In the joint venture, the issues of technology transfer can be resolved in two ways as shown in Figure 1, the interaction of the social and economic effect of the innovation.

1. Individual agreements or a technology transfer contract in an appropriate form (license for a patent, know-how transfer, technical support, and assistance, engineering), that is concluded along with the joint venture agreement, and it's sometimes considered as the part of this agreement.

2. The transferred technology, information, knowledge on management and marketing are considered as a contribution of the intangible asset to the charter capital of the joint venture by one of the parties. However, the incorrect assessment of this contribution can cause significant damage to the joint venture. If the cost (for example, technology) is overvalued, the overall capital structure of the joint venture is affected, the owner of the technology will receive inflated revenues and a high share of capital in the event of the termination of company business. Even if the invested technology becomes obsolete or the know-how loses its "secret" status, it will retain its value as the technology is capitalized. Moreover, its value may increase along with the increment in assets of the joint venture. On the other hand, the acquisition of technology at the start of a joint venture can play an important role as it saves financial resources. Also, the investor will be interested in the continuous improvement of the invested technology, since he directly gains a profit from the implementation of the technology.

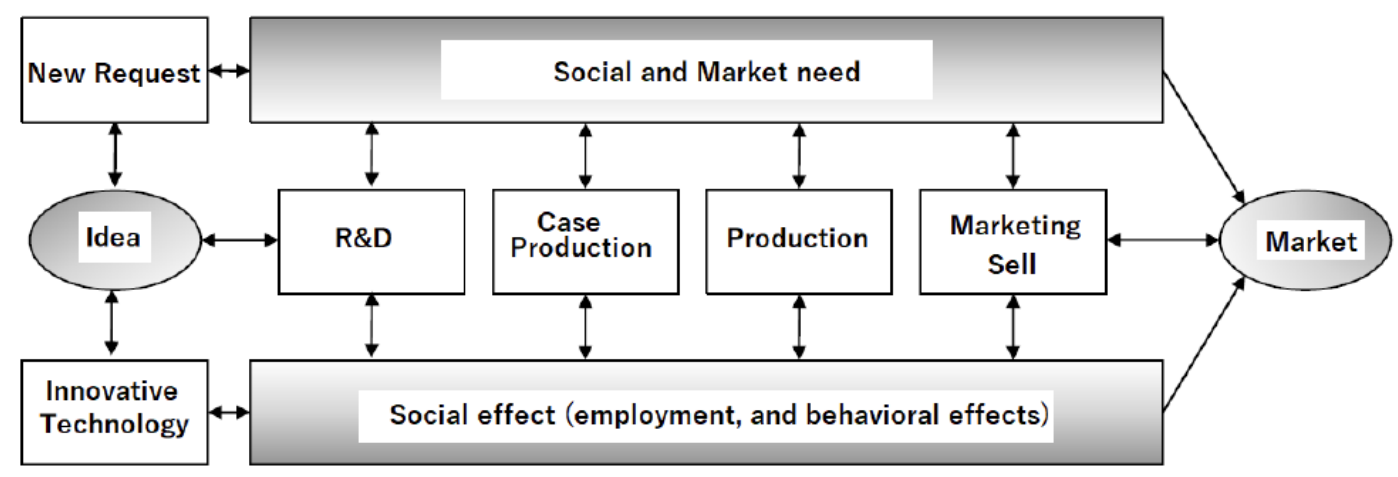

Figure 1: Social and economic effect of the innovation. 


\section{DISCUSSION}

Improving the business environment and improving its measurement indicators in the global arena is not only a positive and fundamental step to strengthen the private sector participation in the economy, improving employment and production in the country, but also creates the conditions for attracting investors, these results are in agreement with the results in the previous studies (Hancock et al., 2019; Franceschelli et al., 2018). External and facilitate the flow of technology into the country and commercialization processes provide new ideas, products, and services. Familiarity with the business environment as well as familiarity with the factors promoting and hindering infrastructure, cultural, social, political, and economic in the development of entrepreneurship and business is also important. The right environment will become a platform for the growth and development of entrepreneurs and entrepreneurial activities. Everything affects the activities of the business, but it is not part of the unit is called the business environment (de Mello et al., 2019). Therefore, it can be said that the most basic role of an entrepreneur is to understand the environmental economic environment in which he intends to start an activity. Therefore, studying and recognizing solutions to eliminate or weaken the effect of these barriers in the country is part of the main goal. On the other hand, a part of the Iranian business community shortly, should be familiar with the business environment and how to monitor and influence it so that the path to success of their business is more carefully planned.

Production cooperation. A quite significant volume of technology is transferred in the process of production cooperation. As a rule, the parties, incorporated to organize the cooperative production, intensively exchange the technologies to achieve the goal. Agreements on cooperation in production go beyond direct or mutual deliveries (sales and purchases) of products or services and create a longterm community of interests between the parties aimed at obtaining additional mutual benefits.

Franchising. According to the experts of the World Intellectual Property Organization, franchising is an agreement whereby one person (rightsholder or franchisor), who has developed a system of conducting certain activities, allows another person (franchisee) to use this system according to the owner's requirements in exchange for a fee. A franchise system is a package of contracts covering intellectual property rights, including the rights to industrial designs, trade names, trademarks, technologies, and know-how that the franchisee will use. In this case, the rights are transferred for a certain period and the franchisee receives significant income from its business activity. The growth in the number of franchising contracts has been a consequence of the high market flexibility of this form of business. The franchising contract allows the franchisor to enter a new market without significant investments and the franchisee can start a new type of business with minimum risk of failure thanks to the support of the franchisor. For the consumer, franchising expands the choice of goods and services in the local market with appropriate (often guaranteed) brand quality and competitive prices.

Leasing (financial lease). Three parties are involved in leasing operations - the lessor, the lessee, and the supplier (manufacturer). The lessor is a specialized leasing company operating with financial resources and controlled by banks or large industrial companies. The lessee is a manufacturing or trading enterprise that leases the means of production, delivery, and distribution. The supplier is a manufacturing or trading company that manufactures or supplies equipment and technology through the lessor to the lessee. In practice, most often technological equipment, expensive machines, instruments, construction and computer equipment, cars, made at the level of invention and protected by patents are usually leased.

The mechanism of innovation commercialization may vary based on the readiness for production, the source of financing, possible partnerships, and other factors. However, in one sequence or another, it will reflect the action mechanism of the above forms of commercialization. Thus, choosing the form of introduction of innovations into the economic turnover is a complex task, its solution involves the correlation and comparison of several alternatives to obtain the maximum benefit from the use of the intellectual property (Hudders et al., 2020).

In the 1990s the economy entered a new stage of development, a new global economy was formed. In this new economy or the knowledge-based economy, the intellectual capital becomes the main capital. It raises doubts about many of the fundamental ideas associated with business and operating companies. The development strategy of most companies in the production of high-technology science-intensive products. The success of a company in the market is critically determined by the competitiveness of its 
products. Innovations in the form of new products, new services, and new technologies are now becoming the most important means of competition. Competitiveness of innovations is one of the strategically important aspects of the Russian economy.

The commercialization of technologies requires skilled personnel - specially trained people who are proficient in the methods of technology management and marketing, knows the necessary legal and regulatory framework in the field of intellectual property, tax, and customs regulations. The concept of management in the science and technology area is just being formed, and the problems remain in the development process of innovation commercialization. There is a glaring dearth of innovative managers who would contribute to a more efficient and dynamic expansion of innovations - from an idea to a finished marketable product or service - in Russia. It has been said that Russians in the technology business still often limit themselves to the role of engineers rather than managers. Finally, the success of an innovative project is determined by the level of management. Investors give attention not to the beauty and unique character of the project, but to the qualifications of the people they trust to manage the invested funds. The current intellectual potential of Russia (estimated at $\$ 400$ billion) can become the basis for its resuscitation if the innovations come into the industry and enter the market. Based on expert estimates, the country will be able to receive amounts comparable to the country's budget through the sale of licenses, developments, execution of external orders, implementation of joint international innovative projects.

The commercialization of innovation is the activity of bringing innovation to the market. In the process of innovation commercialization, the results of scientific research take a commodity form. They are manufactured in the form of a commercial product, have a use-value determined by demand, competitive advantages, and signs of ownership. The commercialization of innovations is an important stage of innovative activity in terms of the returns on investment associated with the development and production of the innovation. At this stage, the rate of return of all innovative companies is formed to a large extent. The inferiority of Russia in terms of competitiveness is largely connected to the ineffective implementation of the innovation commercialization process.

\section{CONCLUSIONS}

In conclusion, it can be said that the main participants of the commercialization process are the creators of innovations (research teams, small and medium innovative enterprises, as well as individual scientists and inventors) and potential investors. Such participants of the commercialization process as commercialization (or technology transfer) centers, business incubators, technology parks, consulting companies, innovation centers, etc. are critical in the innovation commercialization process. Not being investors, they provide significant assistance in the commercialization of technologies and fundraising.

Under the innovation-based economic conditions, intellectual property becomes not only the most important competitive differentiator of high technology products but also the subject of purchase and sale contracts, therefore it forms the market of innovations. Researchers point out that trade in the intellectual product is strictly targeted at a specific consumer. In that respect, one of the most traditional characteristics of goods turnover, i.e. an undefined consumer and the associated uncertainty in the demand pattern for a product, are excluded. At the same time, the regulation function of free supply and demand remains in force (we consider the information), but with a more limited scope.

\section{REFERENCES}

Belcher, B., \& Schreckenberg, K. (2007). Commercialisation of non-timber forest products: A reality check. Development Policy Review, 25(3), 355-377. https://doi.org/10.1111/j.1467-7679.2007.00374.x

Budovich, L. (2019). Special aspects of innovative product development by knowledge-intensive businesses in the current economic conditions. International Journal of Innovative Technology and Exploring Engineering, 8(12), c. 2053-2055.

https://doi.org/10.35940/ijitee.L3255.1081219

Chesalin A.N., Grodzenskiy S.Y., NilovM.Yu., Agafonov A.N. (2019). Modification of the WaldBoost algorithm to improve the efficiency of solving pattern recognition problems in real-time. Russian Technological Journal, 7(5):20-29. (In Russ.) https://doi.org/10.32362/2500-316X-2019-7-5-20-29

Cillo, V., Petruzzelli, A. M., Ardito, L., \& Del Giudice, M. (2019). Understanding sustainable innovation: A systematic literature review. Corporate Social Responsibility and Environmental Management, 26(5), 1012-1025. https://doi.org/10.1002/csr.1783

de Mello, N. G. R., Gulinck, H., Van den Broeck, P., \& Parra, C. (2020). Social-ecological sustainability of non-timber forest products: A review and theoretical considerations for future research. Forest Policy and Economics, 112, 102109. https://doi.org/10.1016/j.forpol.2020.102109

Hancock, K. (2019). Environmental influences on sheriff perceptions and strategies. International journal of criminology and sociology, 8, 100-112.

https://doi.org/10.6000/1929-4409.2019.08.11 
Hudders, L., De Jans, S., \& De Veirman, M. (2020). The commercialization of social media stars: a literature review and conceptual framework on the strategic use of social media influencers. International Journal of Advertising, 7, 149.

https://doi.org/10.1080/02650487.2020.1836925

Franceschelli, M. V., Santoro, G., \& Candelo, E. (2018). Business model innovation for sustainability: a food start-up case study. British Food Journal, 2, 98-104. https://doi.org/10.1108/BFJ-01-2018-0049

Malec, M., Stańczak, L., \& Ricketts, B. (2020). Integrated Commercialization Model of Research and Development
Project Results. Management Systems in Production Engineering, 28(4), 228-239.

https://doi.org/10.2478/mspe-2020-0033

Piccarozzi, M. (2017). Does social innovation contribute to sustainability? The case of Italian innovative start-ups. Sustainability, 9(12), 2376. https://doi.org/10.3390/su9122376

Spender, J. C., Corvello, V., Grimaldi, M., \&Rippa, P. (2017) Startups and open innovation: a review of the literature. European Journal of Innovation Management, 6, 1892-1901. https://doi.org/10.1108/EJIM-12-2015-0131

Received on 19-12-2020

Accepted on 27-01-2021

Published on 01-02-2021

DOI: https://doi.org/10.6000/1929-4409.2021.10.40

(c) 2021 Budovich Lidia Sergeevna; Licensee Lifescience Global.

This is an open access article licensed under the terms of the Creative Commons Attribution Non-Commercial License (http://creativecommons.org/licenses/by-nc/3.0/) which permits unrestricted, non-commercial use, distribution and reproduction in any medium, provided the work is properly cited. 